\title{
Editorial
}

\section{Postdecompressive Craniectomy Surgery, Ventriculomegaly, or Hydrocephalus Development: Imaging, Prevention, and Management}

Decompressive craniectomy surgery (DCS) is increasingly recognized and utilized to manage medically refractory raised intracranial pressure (ICP) ${ }^{[1]}$ It also carries complications, i.e. subdural effusion $(11 \%-62 \%)$, herniation of the cortex through the craniectomy bone defect $(<50 \%)$, seizure $(4 \%-20 \%)$, and others..$^{[2]}$ Further, isolated hydrocephalus or hydrocephalus development associated with subdural hygroma is increasingly recognized as major complication of DCS, and few of them may require cerebrospinal fluid (CSF) diversion surgery. Hydrocephalus can develop either acutely in the immediate perioperative period following DCS surgery or chronic variety being diagnosed during follow-up period while awaiting cranioplasty. It could be either obstructive or rarely communicating variety.

However, dissimilar definitions of hydrocephalus and study inclusion and definition criteria in the past study utilized for the assessment and management of hydrocephalus led to nonuniformity of use of the terms "ventriculomegaly and hydrocephalus" and consequently resulted in very wide variation of reported incidence ranging from $0.7 \%$ to $88 \% .^{[2]}$ In the past, few study relied solely on computed tomography (CT) scan criteria for selection of hydrocephalus cases, whereas few study utilized combination of radiological and clinical features criteria and recent trend is combining clinicoradiological evaluation findings in addition to assessment of intraoperative CSF pressure monitoring to differentiate ventriculomegaly with cases of true hydrocephalus and aid in deciding need of appropriate CSF diversion surgery methods and sparing other of surgery and shunt-related complications..$^{[1-3]}$

Various hypotheses are postulated regarding the pathophysiological mechanism of ventriculomegaly development following DCS and include abnormality of CSF circulation pathway, leading to CSF malabsorption due to blood or blood products entering into subarachnoid spaces and retarding or obstructing CSF flow, thereby promoting CSF accumulation. According to another postulate, DCS may cause "flattening" effect on the normally dicrotic CSF pulse wave as a pressure pulse get transmitted out through the cranial defect and retards CSF circulation. ${ }^{[3]}$ Another postulate is disruption of pulsatile ICP leads to loss of pressure gradient between the subarachnoid space and draining venous sinuses and results in reduced CSF outflow and absorption, promoting communicating variety of hydrocephalus. However, obstructive hydrocephalus may develop due to presence or extension of hemorrhage in the intraventricular cavity or subarachnoid space. Thus, the diminished CSF absorption leads to increasing accumulation, resulting in the development of chronic hydrocephalus. [2-6] The acute variety of hydrocephalus is chiefly caused by sudden intraventricular obstruction. In few cases, ventriculomegaly may not represent raised ICP but simply represent cerebral atrophic process caused as sequelae of previous diffuse brain injury. ${ }^{[2]}$

The development of hydrocephalus may be preceded by the formation of the subdural hygroma in the interhemispheric fissure and also regarded as a precursor of hydrocephalus. ${ }^{[4]}$ Kaen et al. observed about $85 \%$ of their cases had hygroma formation and preceded the development of hydrocephalus and aptly proposed two phases; first being the rebound phase, characterized by exertion of traction effect over falx cerebri following DCS causing expansion of interhemispheric space and accumulation of hygroma and next phase is hydrodynamic phase associated with accumulation of subdural collection space over cerebral convexity and well established hydrocephalus development. ${ }^{[4]}$

The differentiation of ventriculomegaly from true hydrocephalus, the concordance of clinico-radiological evaluation findings, and further correlation with subdural pressure monitoring value should be currently regarded as essential criteria for labeling as hydrocephalus. The clinical evaluation should include Glasgow Coma Scale (GCS) score, Mini-Mental Scale examination score, fundi evaluation, assessment of clinical neurological progressing or deterioration over time or failure to showing neurological improvement, and evidence of clinical improvement after ventriculoperitoneal (VP) shunt surgery and local examination of skull showing the presence of tense bulging brain beyond the confines of craniectomy defect. Similarly, detailed neuroimaging parameters' evaluation should include the presence of ventriculomegaly with an Evan's index $>0.3$, association of enlarging extra-axial collection or narrowed CSF spaces at the convexity on serial cranial CT scan, presence of transependymal edema, and expansion of brain beyond confines of craniectomy defects. Huh et al. advocated intraoperative subdural pressure measurement 
using manometer, just before dural opening in patients with subdural collections and ventriculomegaly. These clinicoradiological and intrcranial CSF pressure criteria are important and needs very judicious utilization. ${ }^{[6]}$

This stringent application of clinicoradiological hydrocephalus criteria led to significant reduction in labeled cases of ventriculomegaly as hydrocephalus. Rahme et al. found the incidence of hydrocephalus after DCS was $0 \%$ in their retrospective study involving 17 patients. ${ }^{[5]}$ Various management options may include observation with close monitoring using serial cranial CT scan, VP shunt surgery, or theco-peritoneal shunt surgery depending on facility and choice surgeons, expertise and appropriate indication, and strict patient selection criteria.

Kutty et al. analyzed 21 cases awaiting or undergoing cranioplasty following DCS procedure, developing ventriculomegaly were assigned into two groups; fist group consisted of direct VP shunt surgery and another group involved ventricular tapping. Patients were clinically evaluated using GCS score, papilledema, and Evans Index on CT scan. The complications included overdrainage of shunts in two cases in the first group and in another group, one case developed intracerebral bleed following cannulation of ventricle for CSF drainage. Authors observed appropriate clinical and radiological parameters were highly helpful in identifying true hydrocephalus cases needing CSF diversion surgery. In addition, intrcranial pressure was monitored in five cases in the ventricular tapping group, who were managed with ventricular drain for assisting cranioplasty and noted it was also proven to be helpful. ${ }^{[7]}$

Various probable risk factors for hydrocephalus development include bilateral DCS, the distance of craniectomy margin $<2.5 \mathrm{~cm}$ from the midline, cerebral vascular disease as primary pathology for DCS indication, presence of subarachnoid hemorrhage, intraventricular bleed, relatively older age, injury severity, maximum ICP level rise before decompression surgery, and GCS Score at admission, presence of subdural or interhemispheric hygroma, delayed cranioplasty, repeated surgery, and duraplasty. As these patients need careful observation for early detection and prompt therapeutic intervention.

It is highly recommended detailed clinical evaluation in conjunction with appropriate and desirable neuroimaging study, if both the finding are concordant; it definitely helps in selecting hydrocephalus patients; however, addition of CSF pressure monitoring will definitely eliminate the cases of ventriculomegaly not needing any kind of temporary or permanent CSF diversion surgery. In analysis of 13 cases of ventricular dilation, Lin et al. observed no direct association between the extent of ventriculomegaly and neurological status, and further noted VP shunt placement surgery may not help in promoting neurological improvement and warned against poor selection of cases; in addition, it puts patient on the risk of shunt placement surgery-related complications, i.e. overdrainage and malfunction. ${ }^{[8]}$ Hence, stringent patient selection criteria can drastically reduce the need for CSF diversion surgery, and surgery should be offered to selected cases showing significant clinicoradiological concordant and the judicious use of CSF pressure monitoring, if feasible and facility exist for such monitoring values. ${ }^{[5,7]}$ As it is evident with a study by Rahme et al. observed $0 \%$ incidence of hydrocephalus after DCS with the application of stringent diagnostic criteria for labelling the diagnosis of hydrocephalus. ${ }^{[5]}$

Guru Dutta Satyarthee

Department of Neurosurgery, Neurosciences Centre, AIIMS, New Delhi, India

Address for correspondence: Dr. Guru Dutta Satyarthee, Department of Neurosurgery, Neurosciences Centre, AIIMS, Room No. 714, New Delhi, India. E-mail: duttaguru2002@yahoo.com

\section{REFERENCES}

1. Agrawal D, Pandey N, Sinha S, Gupta D, Satyarthee GD, Singh PK. Subdural effusion with ventriculomegaly after decompressive craniectomy for traumatic brain injury: A challenging entity. Ind J Neurotrauma 2014;11:97-102.

2. Ding J, Guo Y, Tian H. The influence of decompressive craniectomy on the development of hydrocephalus: A review. Arq Neuropsiquiatr 2014;72:715-20.

3. Waziri A, Fusco D, Mayer SA, McKhann GM, Connolly ES Jr. Postoperative hydrocephalus in patients undergoing decompressive hemicraniectomy for ischemic or hemorrhagic stroke. Neurosurgery 2007;61:489-93.

4. Kaen A, Jimenez-Roldan L, Alday R, Gomez PA, Lagares A, Alén JF, et al. Interhemispheric hygroma after decompressive craniectomy: Does it predict posttraumatic hydrocephalus? J Neurosurg 2010;113:1287-93.

5. Rahme R, Weil AG, Sabbagh M, Moumdjian R, Bouthillier A, Bojanowski MW, et al. Decompressive craniectomy is not an independent risk factor for communicating hydrocephalus in patients with increased intracranial pressure. Neurosurgery 2010;67:675-8.

6. Huh PW, Yoo DS, Cho KS, Park CK, Kang SG, Park YS, et al. Diagnostic method for differentiating external hydrocephalus from simple subdural hygroma. J Neurosurg 2006;105:65-70.

7. Kutty RK, Sreemathyamma SB, Sivanandapanicker J, 
Asher P, Prabhakar RB, Peethambaran A, et al. The conundrum of ventricular dilation following decompressive craniectomy - Is Ventriculoperitoneal Shunt, the only panacea. J Neurosci Rural Pract 2018;9:232-9.

8. Lin BJ, Chou KN, Feng SW, Ju DT, Ma HI, Hueng DY, et al. Role of post-decompressive hydrocephalus in patients with malignant cerebral infarction. Turk Neurosurg 2015;25:742-8.

This is an open access journal, and articles are distributed under the terms of the Creative Commons Attribution-NonCommercial-ShareAlike 4.0 License, which allows others to remix, tweak, and build upon the work non-commercially, as long as appropriate credit is given and the new creations are licensed under the identical terms.

\begin{tabular}{|c|c|}
\hline \multicolumn{2}{|c|}{ Access this article online } \\
\hline $\begin{array}{l}\text { Quick Response Code: } \\
\end{array}$ & $\begin{array}{l}\text { Website: } \\
\text { www.ruralneuropractice.com }\end{array}$ \\
\hline 64taris & $\begin{array}{l}\text { DOI: } \\
\text { 10.4103/jnrp.jnrp_547_17 }\end{array}$ \\
\hline
\end{tabular}

How to cite this article: Satyarthee GD. Postdecompressive craniectomy surgery, ventriculomegaly, or hydrocephalus development: Imaging, prevention, and management. J Neurosci Rural Pract 2018;9:177-9. 